\title{
A ELETROMIOGRAFIA COMO AUXÍLIO NA CONDUTA TERAPÊUTICA APÓS CIRURGIA DE CRANIOTOMIA FRONTO-TEMPORAL: RELATO DE CASO
}

\author{
Electromyography as an aid in therapeutic behavior \\ after fronto-temporal craniotomy surgery: case report
}

\author{
Maristella Cecco Oncins ${ }^{(1)}$, Carlos Roberto Douglas ${ }^{(2)}$, Guiovaldo Paiva ${ }^{(3)}$
}

\begin{abstract}
RESUMO
Tema: eletromiografia e conduta terapêutica. Procedimentos: este estudo foi realizado com uma paciente de 45 anos de idade, após 4 meses ser submetida a craniotomia fronto-temporal proveniente de um aneurisma. O músculo temporal anterior direito foi retirado da sua origem móvel e após a cirurgia, a paciente apresentou disfunção do músculo temporal e da articulação temporomandibular, com redução da abertura de boca, dor ao falar e comer. Utilizou-se a eletromiografia para registrar quantitativamente a atividade elétrica dos músculos temporais e masseteres na avaliação e durante o processo terapêutico. Registraram-se, na posição de repouso, oclusão máxima e mastigação habitual provocada. Fez-se terapia miofuncional durante todo o processo. Resultados: dados dos exames mostraram um aumento significativo da atividade elétrica do músculo temporal anterior direito e uma redução da atividade do músculo temporal anterior esquerdo, o que no primeiro registro mostrava uma atividade elétrica rebaixada do lado direito em comparação com o lado esquerdo. Com a seleção dos exercícios miofuncionais houve uma participação mais efetiva do músculo temporal anterior direito, abertura de boca maior, sem dor, facilitando a função da mastigação e da fala, harmonizando o sistema estomatognático. Conclusão: registros comparativos dos exames de eletromiografia em diferentes etapas do processo terapêutico auxiliaram e direcionaram a melhor conduta terapêutica fonoaudiológica. Conseguiu-se atingir um equilíbrio das funções de respiração, sucção, mastigação, deglutição e fala relacionadas ao sistema estomatognático, considerando as limitações do caso.
\end{abstract}

DESCRITORES: Sistema Estomatognático; Articulação Temporomandibular; Eletromiografia; Craniotomia

\section{INTRODUÇÂO}

Uma das atuações do fonoaudiólogo na área de motricidade orofacial refere-se a avaliar, prevenir e harmonizar as funções estomatognáticas, ade-

(1) Fonoaudióloga; Membro científico do Centro de Diagnóstico e Tratamento da Articulação Temporomandibular, CDTATM, São Paulo, SP; Mestre em Fonoaudiologia Clínica pela Pontifícia Universidade Católica de São Paulo.

(2) Médico; Professor de Fisiologia e Fisiologia Evolutiva na Universidade Metodista de São Paulo, UMESP, São Paulo, SP; Pós Doutorado pelo Public Health Service (National Institude of Health), U.S.A.

(3) Cirurgião Dentista; Diretor do Centro de Diagnóstico e Tratamento da Articulação Temporomandibular, CDTATM, São Paulo, SP; Especialista em Prótese Dental e Disfunção Temporomandibular e Dor Orofacial.

Conflito de interesses: inexistente quando o tônus e o movimento dos músculos nelas envolvidos, assim como intervir sobre a remoção de hábitos e posturas inadequadas ${ }^{1,2}$.

A observação frequente de desequilíbrios sistemáticos ou preferenciais na mastigação contribuiu para que esta área da Fonoaudiologia aprofundasse o seu conhecimento sobre a fisiologia oral na relação forma/função estomatognática ${ }^{3}$.

Como a função mastigatória refere-se a um complexo integrado por músculos, ligamentos, estruturas ósseas e dentes, além de ser controlado pelo sistema nervoso, os elementos mencionados participariam na execução da função mastigatória, sendo que os músculos realizam movimentos e posturas que ora aproximam, ora afastam os dentes, ou exacerbam a pressão interoclusal ${ }^{2}$. Além do 
mais, a mastigação dá prosseguimento evolutivo à estimulação da musculatura orofacial, iniciada onto/ filogeneticamente pela sucção e deglutição que ocorrem como consequência ${ }^{1}$.

Durante a mastigação, um número considerável de músculos mandibulares entra em funcionamento: basicamente temporal anterior e posterior, masseter, pterigóideo medial e pterigóideo lateral, digástrico, gênio-hióideo, milo-hióideo, bucinador, orbicular dos lábios, zigomático maior e menor, entre muitos outros ${ }^{1}$.

Analisar - de forma objetiva e minuciosa a atividade muscular de grupos musculares em paciente com disfunção temporomandibular, poderia fornecer outro subsídio para complementar a avaliação do sistema estomatognático na clínica fonoaudiológica.

A maioria dos fonoaudiólogos que avalia a atividade muscular da mastigação registra-a por meio de simples observações, filmagens ou/e palpações (exame físico). Embora ricamente empíricos esses dados não são precisos, nem suscetíveis de quantificação, pois são influenciados pela subjetividade do observador, limitando um registro mais preciso.

Atualmente, o desenvolvimento tecnológico permite contar com instrumentos de medição de grande precisão e de uso clínico, dentre os quais se tem a eletromiografia (EMG), método disponível no mercado, há mais de 40 anos, que possui maior objetividade e precisão para registrar a atividade elétrica de um músculo ou de um grupo muscular ${ }^{4}$.

A eletromiografia confirma claramente e pode quantificar a presença e severidade da disfunção elétrica muscular, indicando, por exemplo, qual músculo seria ativado pelo Sistema Nervoso Central em uma determinada função ou atividade. Os níveis de atividades eletromiográficas mostram um perfil de quanto os músculos estariam eletricamente ativos 5. A EMG de superfície é utilizada na clínica, como em pesquisas, na ciência do esporte, e em vários campos distintos ${ }^{6}$. A utilização da eletromiografia, associada aos outros métodos clínicos, permite uma melhor compreensão da participação dos músculos mandibulares no funcionamento do sistema estomatognático, pelo que serve de orientação para eventuais tratamentos deste mesmo sistema ${ }^{7,8}$.

O trabalho com a motricidade orofacial, na Fonoaudiologia, tem como foco prioritário equilibrar o sistema estomatognático, restabelecendo ou adequando às funções de respiração, sucção, deglutição, mastigação e fala, assim como postura e hábitos deletérios.

O objetivo deste relato foi demonstrar a utilização da eletromiografia para confirmar quantitativamente a atividade elétrica dos músculos temporais e masseteres antes e durante o processo terapêutico e auxiliar na conduta terapêutica, após uma paciente ser submetida a cirurgia de craniotomia fronto-temporal.

\section{APRESENTAÇÃO DO CASO}

\section{Características do caso}

Este relato refere-se a uma paciente de 45 anos de idade, sexo feminino, que apresentou quadro de aneurisma e foi submetida à cirurgia para clipagem do aneurisma. Ocorreu uma craniotomia frontotemporal, da artéria cerebral média, e craniotomia pterional. A craniostomia é uma abertura cirúrgica do crânio, com o objetivo de se obter acesso às meninges ou à massa encefálica. Atualmente, vêm sendo empregadas craniostomias pequenas para algumas lesões profundas, como tumores, e cirurgias de aneurisma cerebral.

O músculo temporal anterior direito (MTAD) foi retirado da sua origem móvel por aproximadamente 8 horas, tempo de duração da cirurgia. Após a cirurgia, a paciente apresentou disfunção intensa do músculo temporal anterior direito e disfunção da articulação temporomandibular direita (DATM) sintomas previstos na maioria dos casos pós-cirúrgicos.

Após quatro meses da cirurgia, os sintomas póscirúrgicos persistiram e a paciente procurou tratamento fonoaudiológico com queixa de limitação de abertura de boca, cansaço para falar, dor intensa na região da ATM direita e do músculo masseter direito, dificuldade na função mastigatória para qualquer tipo de alimento, cefaleias ou enxaquecas frequentes.

\section{Avaliação da função estomatognática}

A paciente foi avaliada e atendida em clínica particular e os exames complementares de eletromiografia (EMG) foram realizados no setor de estudos do Centro de Diagnóstico e Tratamento da ATM em São Paulo, sob supervisão da terapeuta. Os exames obtidos só foram realizados após a pesquisadora ter lido e assinado com a paciente e participante as informações necessárias para o consentimento pós-informado. Todos os exames foram realizados pela pesquisadora e terapeuta no caso estudado e posteriormente analisados e discutidos com a equipe.

A avaliação fonoaudiológica focou o sistema estomatognático incluindo as funções relacionadas a este sistema e registrou a postura global da paciente. Utilizou-se o paquímetro digital seis polegadas Lee para registrar a abertura de boca.

A mastigação foi registrada, inicialmente, através de alimento, do tipo pão francês, e não conseguiu abrir a boca para introduzir o alimento. 
Posteriormente ofereceu-se alimento, do tipo bolacha maisena.

Foram realizados exames de eletromiografia para complementar os dados clínicos de uma forma mais objetiva.

Para a realização do exame de EMG, foi utilizado - eletromiógrafo de superfície Sistema BIOPAK, Bioresearch Associates, composto por: Placa especial (Bio PAK); amplificador para 08 canais modelo 800; eletrodos bipolares de superfície (Bio Trodo no gel); fios especiais para conectar os eletrodos ao amplificador; software (Bio PAK para Windows) e computador.

Os exames foram realizados sempre no período da manhã. A sala, com piso forrado de borracha, foi mantida silenciosa e com as janelas sempre fechadas. A iluminação homogênea foi proporcionada por lâmpada de mercúrio, localizada no centro do teto. Permaneceram na sala apenas a pesquisadora e terapeuta, a assistente e a paciente.

Durante os exames a postura da paciente foi padronizada: posição sentada, em uma cadeira com suporte para a região das costas; em posição ereta com os pés paralelos e apoiados no chão; com os membros, superiores e inferiores, relaxados e descruzados, mãos sobre as coxas; a mandíbula em posição paralela ao solo; a cabeça sem apoio, favorecendo uma postura mais espontânea e adequada na relação da cabeça e do pescoço ${ }^{5}$.

Esta posição foi escolhida porque pesquisas acerca dos músculos mandibulares, sob o ponto de vista de seu tônus de postura, apontaram maior atividade eletromiográfica na posição de 90 graus (indivíduo sentado em ângulo reto), que vai diminuindo até chegar à posição de zero grau (indivíduo deitado em posição supina). Em posição sentada, a força gravitacional age na mesma direção e sentido das fibras mastigatórias, enquanto que a mesma força age formando ângulo reto na posição decúbito, quando a mandíbula sofre maior atração pela força gravitacional, favorecendo a abertura de boca ${ }^{9}$. Então, em pé ou sentado, com menor atração gravitacional, a mandíbula se situa em posição mais alta. Nessa posição já padronizada procedeuse ao exame de EMG.

Para a EMG, utilizaram-se quatro canais para monitorar os músculos: temporal (feixe anterior) esquerdo e direito, masseter, feixe superficial, esquerdo e direito. Foi utilizado um único eletrodo monopolar na região do músculo esternocleidomastoideo esquerdo para identificar um ponto neutro (fio terra). Os registros foram simultâneos e bilaterais.

Dado que variações relativamente pequenas na colocação de eletrodos podem interferir na eletromiografia, não há a possibilidade de comparar registros feitos em diferentes situações. Nesta pesquisa este cuidado foi considerado e os registros ocorreram no período da manhã e a colocação dos eletrodos foi cautelosa.

Para a captação dos sinais elétricos dos músculos, empregaram-se eletrodos duplos de superfície, descartáveis, contendo um gel condutor. Os eletrodos, bipolares, foram colocados sobre os músculos na região muscular de maior volume. Para fixar o eletrodo no músculo masseter, solicitou-se a participante que ocluísse os dentes, pressionandoos. Mediante palpação digital simultânea da musculatura desejada, localizou-se a região de maior volume, instalou-se o eletrodo bipolar, paralelo às fibras musculares, localizado aproximadamente a 3 $\mathrm{cm}$ acima e anterior ao ângulo da mandíbula. Os locais de superfície onde foram instalados os eletrodos eram previamente limpos e pressionados com gaze embebida em álcool gel etílico hidratado $70^{\circ}$ INPM, com a finalidade de retirar a gordura da pele ou outros resíduos que pudessem prejudicar a aderência dos eletrodos e passagem da corrente elétrica. Dessa forma solicitou-se a paciente não usar qualquer creme, protetor ou base facial antes do exame, com o intuito de eliminar qualquer interferência nos sinais ou na aderência dos eletrodos na pele. Para a instalação do eletrodo na região do músculo temporal, também se palpava o local do referido músculo durante a oclusão, fixando o eletrodo duplo na região anterior de maior volume muscular, próximo à sutura parietal.

Ligou-se o computador, instalaram-se os eletrodos nas musculaturas desejadas e as conexões estabelecidas para a execução dos testes, usouse um fio condutor com duas extremidades livres; uma delas foi conectada a um amplificador que leva as informações para o computador e permanece no ponto de referência, como um colar, e a outra conectada com os eletrodos dos músculos que foram analisados (Figura 1).

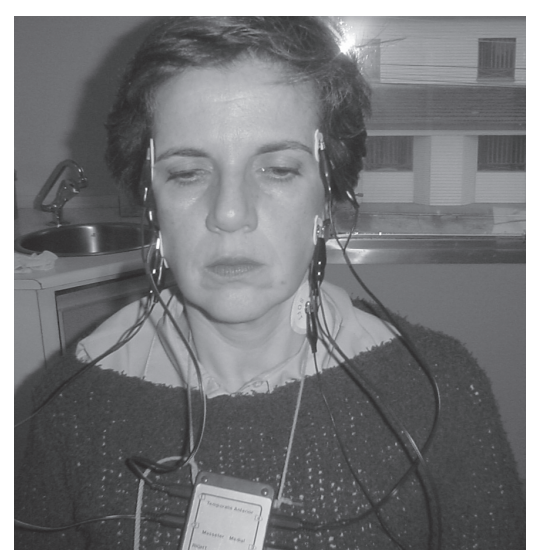

Figura 1 - Fio condutor com duas extremidades: uma conectada ao eletrodo de superfície e a outra conectada ao amplificador (Oncins, 2004) 
Registrou-se a EMG na posição de repouso. Neste momento a paciente foi convidada a permanecer relaxada, com os lábios fechados e dentes levemente desocluídos. O registro da atividade elétrica de cada músculo foi computado em um período de 10 segundos. Para determinar valores de referência, na posição de repouso, determinou-se o valor médio das atividades elétricas musculares em microvolt, registradas pela EMG no início, meio e final de um período de 10 segundos.

Registrou-se a EMG em oclusão máxima e durante a mastigação habitual provocada com uva passa durante os doze primeiros ciclos mastigatórios consecutivos. A seleção ocorreu por ciclo mastigatório, sem considerar a velocidade habitual do indivíduo.

Na mastigação habitual provocada, ofereceramse três uvas passas sem caroço. A paciente manteve $o$ alimento sobre a língua por alguns instantes, os lábios fechados e os dentes levemente ocluídos antes de dar inicio à mastigação. Tal posição é considerada ideal para eliminar alguma possível interferência eletrônica no registro. Então, solicitou-se a paciente mastigar o alimento como de costume, observando o exame no computador para o registro da atividade elétrica muscular através da EMG (Figura 2).

Durante os registros da mastigação, a paciente foi solicitada a permanecer sem falar e sem movimentar a cabeça.

As sessões miofuncionais foram planejadas e reavaliadas constantemente pela clínica e complementada pelos resultados das atividades elétricas registradas pelos exames de EMG.
Os procedimentos deste estudo de caso foram aprovados pela Comissão de Ética em Pesquisa do CEFAC - Saúde e Educação, sob número 013/08.

Os testes de EMG, para registrar a atividade elétrica, em microvolts, dos músculos masseteres e temporais anteriores direito e esquerdo na posição de repouso, oclusão e mastigação habitual provocada com uva passa foram realizados todos na avaliação, outros após cinco, oito e 12 meses do início do processo terapêutico.

\section{Fonoterapia}

O processo terapêutico iniciou-se com sessões de 40 minutos, duas vezes por semana nos primeiros três meses passando a uma vez por semana até o oitavo mês e a cada 15 dias até completar 1 ano de terapia. A paciente foi orientada a realizar a sequência de exercícios, selecionada pela terapeuta, no mínimo três vezes ao dia.

Nas sessões trabalharam-se as funções do sistema orofacial relacionadas ao sistema estomatognático, como: respiração; sucção; mastigação; deglutição e articulação da fala. Os pares cranianos considerados e estimulados nestas funções foram: olfatório (I); trigêmio (V); facial (VII); glossofaríngeo (IX); hipoglosso (XII); vago (X) e acessório (XI), enfatizando que os dois últimos foram mais relacionados com a postura da cabeça e do pescoço.

\section{RESULTADOS}

Na avaliação fonoaudiológica, quando a paciente falava, observou-se dificuldade em articular as palavras, tensão na região cervical e no músculo esternocleidomastóideo, mais acentuada do lado

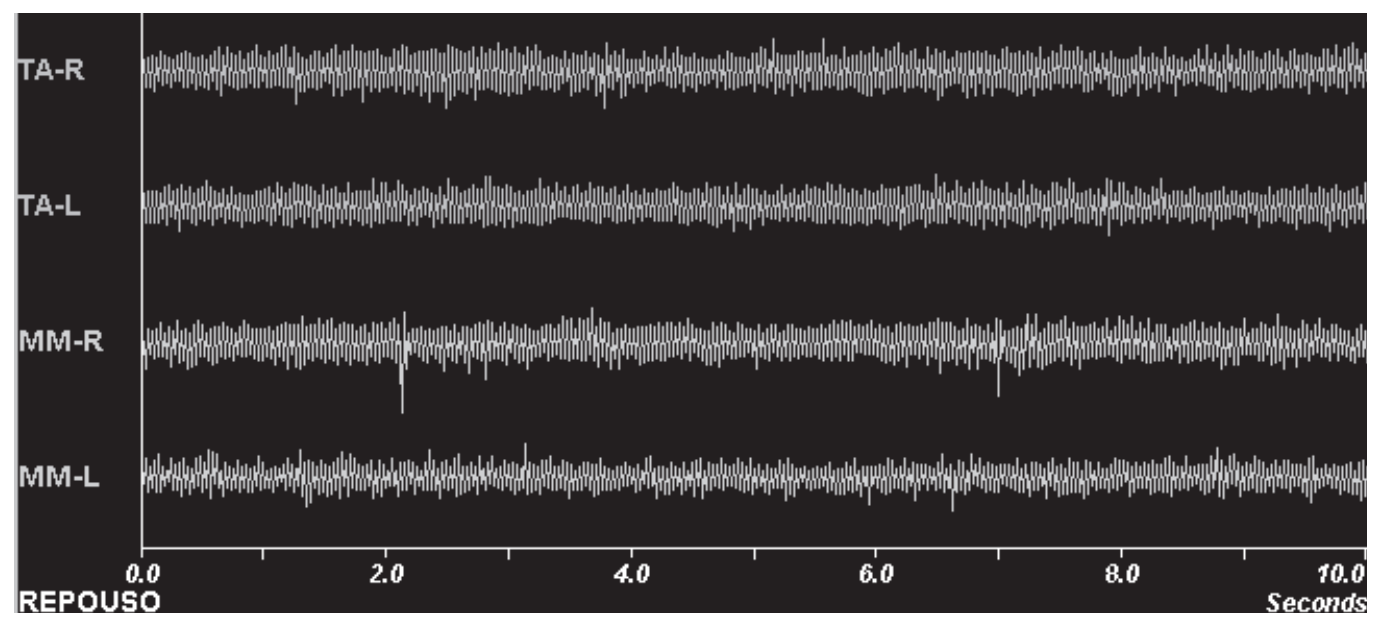

Legenda: TAD = músculo temporal anterior direito; TAE = músculo temporal anterior esquerdo; $\mathrm{MMD}=$ músculo masseter direito; $\mathrm{MME}=$ músculo masseter esquerdo

\section{Figura 2 - Registro da ENMG na posição de repouso em um período de 10 segundos}


esquerdo. Postura corporal alterada na posição sentada, tronco desviado do eixo central, reclinado para o lado direito com apoio e pressão da mão direita na hemi mandíbula direita - segundo informações da paciente mantinha essa postura - para tentar aliviar a dor na região e a cefaléia na região temporal direita.

Com o paquímetro digital, registrou-se $18 \mathrm{~mm}$ de abertura máxima de boca na avaliação. Após a décima terceira sessão registrou-se $33 \mathrm{~mm}$ de abertura máxima sem dor e após 24 sessões registrouse $36 \mathrm{~mm}$ de abertura sem esforço e sem dor.

$\mathrm{Na}$ avaliação, pela palpação relatou-se dor intensa na região do músculo masseter direito e na região da ATM direita. Durante a posição de repouso observou-se respiração predominantemente superior, tipo nasal, e ao falar notou-se uma incoordenação pneumofonoarticulatória. A função de sucção mostrou-se alterada pela dificuldade de abertura de boca e dor. A atuação dos músculos bucinadores, orbicular da boca e mentual durante esta função foram quase inexistentes pela palpação.

Ao mastigar bolacha fazia os movimentos mastigatórios com movimentos associados de cabeça no plano vertical, abaixando-a e levantando-a.

Na função mastigatória observaram-se ausência de lateralização mandibular para ambos os lados durante a mastigação e execução de exercícios solicitados para tal movimento. Durante a função mastigatória, não foi observada a atuação do músculo temporal anterior direito e levíssima atuação do músculo masseter direito verificado através da palpação.

No exame de eletromiografia, os resultados das mensurações das atividades elétricas dos músculos em estudo, na posição de repouso, na oclusão máxima e na mastigação habitual provocada com uva passa.

Os resultados da atividade elétrica, através da EMG, na posição de repouso, na avaliação e após 12 meses de terapia, e médias dos valores estabelecidas por Jankelson ${ }^{10}$ podem ser observados na Tabela 1.

$\mathrm{Na}$ Tabela 2 apresenta-se o registro da atividade elétrica em oclusão máxima que ocorreram na avaliação, após cinco, oito e 12 meses e na Figura 3 a oclusão máxima na avaliação e após 12 meses. Nota-se que o músculo comprometido na craniotomia, o temporal anterior direito desde o período da avaliação até o último registro, aumentou quase quatro vezes - 393\%, passando de $7,09 \mu \mathrm{v}$ para 27,9 $\mu \mathrm{v}$ e o músculo temporal anterior esquerdo diminuiu $38 \%$, passando de $92,19 \mu \mathrm{v}$ iniciais para $57,44 \mu \mathrm{v}$ finais. A diferença das atividades elétricas entre os músculos temporais anteriores bilaterais no último registro é bem menor que no inicial, o que pode ser

Tabela 1 - Resultados da atividade elétrica muscular na posição de repouso na avaliação $(A)$ e após 12 meses (B) e os valores estabelecidos por Jankelson (C)

\begin{tabular}{ccccc}
\hline Origem & $\begin{array}{c}\text { Músculo Temporal } \\
\text { Anterior Direito }\end{array}$ & $\begin{array}{c}\text { Músculo Temporal } \\
\text { Anterior Esquerdo }\end{array}$ & $\begin{array}{c}\text { Músculo Masseter } \\
\text { Direito }\end{array}$ & $\begin{array}{c}\text { Músculo Masseter } \\
\text { Esquerdo }\end{array}$ \\
\hline $\mathrm{A}(\mu \mathrm{V})$ & 0,7 & 1,2 & 0,6 & 0,5 \\
$\mathrm{~B}(\mu \mathrm{V})$ & 1,6 & 1,5 & 1,0 & 1,1 \\
$\mathrm{C}(\mu \mathrm{V})$ & $1,5-2,5$ & $1,5-2,5$ & $1,0-2,0$ & $1,0-2,0$ \\
\hline
\end{tabular}

Legenda: $A=$ média dos valores da atividade muscular registrada na posição de repouso em período de 10 segundos na avaliação; $\mathrm{B}=$ média dos valores da atividade muscular registrada na posição de repouso em período de 10 segundos após 12 meses de terapia; $\mathrm{C}=$ média dos valores da atividade muscular registrada por Jankelson (1990); $\mu \mathrm{V}=$ microvolt

Tabela 2 - Resultados da atividade elétrica muscular na oclusão máxima na avaliação (A); após 5 meses (B); 8 meses (C) e após 12 meses (D) de terapia

\begin{tabular}{ccccc}
\hline Origem & $\begin{array}{c}\text { Músculo Temporal } \\
\text { Anterior Direito }\end{array}$ & $\begin{array}{c}\text { Músculo Temporal } \\
\text { Anterior Esquerdo }\end{array}$ & $\begin{array}{c}\text { Músculo Masseter } \\
\text { Direito }\end{array}$ & $\begin{array}{c}\text { Músculo Masseter } \\
\text { Esquerdo }\end{array}$ \\
\hline $\mathrm{A}(\mu \mathrm{V})$ & 7,09 & 92,19 & 16,00 & 37,65 \\
$\mathrm{~B}(\mu \mathrm{V})$ & 20,00 & 60,67 & 61,48 & 69,2 \\
$\mathrm{C}(\mu \mathrm{V})$ & 25,00 & 54,45 & 46,5 & 35.32 \\
$\mathrm{D}(\mu \mathrm{V})$ & 27,9 & 57,44 & 53,82 & 81,23 \\
\hline
\end{tabular}

Legenda: $A=$ média dos valores da atividade muscular registrada na oclusão máxima na avaliação; $B=$ média dos valores da atividade muscular registrada na oclusão máxima após 5 meses de terapia; $\mathrm{C}=$ média dos valores da atividade muscular registrada na oclusão máxima após 8 meses de terapia; $\mathrm{D}=$ média dos valores da atividade muscular registrada na oclusão máxima após 12 meses de terapia; $\mu \mathrm{V}=$ microvolt 


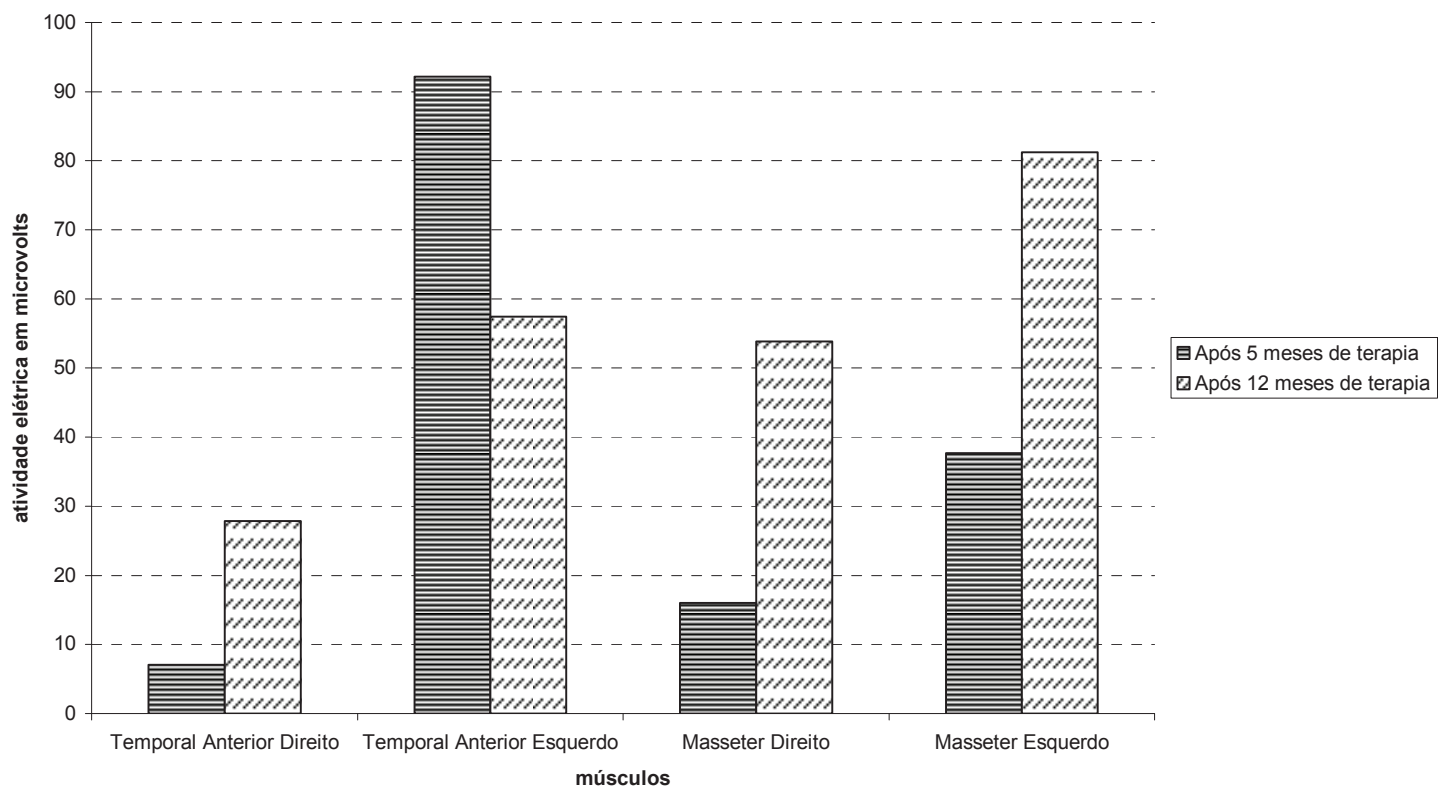

Figura 3 - Registro da atividade elétrica muscular através da eletromiografia na oclusão máxima na avaliação e após 12 meses de terapia

observado na Figura 3. Houve um aumento da atividade elétrica dos músculos masseteres bilaterais: 0 direito, de 3 vezes o valor inicial e o esquerdo de 2 vezes o valor inicial aproximadamente. A diferença entre as atividades elétricas dos masseteres no registro inicial teve uma redução significativa, o que pode ser notado na Figura 3.

As atividades elétricas, na mastigação habitual provocada com uva passa, no período da avaliação e após 12 meses de terapia, dos músculos temporais e masseteres bilaterais, observa-se na Tabela 3 e na Figura 4. O músculo temporal anterior direito teve um aumento aproximado de 3 vezes $-285 \%$ da atividade elétrica inicial, passando de $8,3 \mu \mathrm{v}$ para 23,6 $\mu v$ enquanto que o músculo temporal esquerdo teve uma redução aproximada de $24 \%$ da atividade elétrica inicial, passando de $36,3 \mu \mathrm{v}$ para $27,1 \mu \mathrm{v}$.

\section{DISCUSSÃO}

As disfunções temporomandibulares têm enfoque interdisciplinar. Neste relato de caso os resultados dos exames de EMG e condutas foram analisados por uma equipe de terapeuta especialista em motricidade orofacial, um dentista especialista em disfunção temporomandibular e um fisiologista.

A queixa de cefaléias constantes, dor ao mastigar e limitação na abertura de boca são comuns nas disfunções temporomandibulares ${ }^{11,12}$ e a queixa de cansaço ao falar já se tornam mais frequentes nos estudos de Fonoaudiologia ${ }^{13-15}$.
No caso, a queixa de dores na região do músculo temporal direito e masseter direito; dor e cansaço após falar por um período de tempo se devem a hipoatividade do músculo temporal e masseter direito, após a craniotomia. Esses dados foram confirmados com o exame de eletromiografia, na posição de repouso, na oclusão máxima e na mastigação habitual provocada.

Observa-se, na avaliação, que tanto os músculos temporais anteriores como os músculos masseteres, na posição de repouso, estão fora dos valores de referência de Jankelson. Após um ano de acompanhamento terapêutico os resultados das atividades elétricas dos músculos evidenciaram valores dentro da média dos resultados encontrados na literatura ${ }^{5,10}$.

Uma atividade elétrica elevada em um ou mais músculos, e quase ausente em outros, poderia gerar uma sobrecarga na ATM e naturalmente um desequilíbrio no sistema estomatognático ${ }^{16}$. É importante lembrar que o músculo temporal anterior é um dos músculos que tem como função fundamental manter a mandíbula na posição de repouso e o músculo masseter de levantar a mandíbula, juntamente com o músculo temporal.

Se ocorrer uma sobrecarga e desequilíbrio na musculatura do sistema estomatognático, a paciente poderá apresentar cansaço ao falar e ao comer, devido à dificuldade de movimentação de abaixamento e levantamento da mandíbula ${ }^{15,17}$.

A limitação de abaixamento e levantamento da mandíbula, provocada pela hipoativação do músculo temporal anterior direito, desarmoniza o 
Tabela 3 - Resultados da atividade elétrica muscular mastigação habitual provocada com uva passa no período de avaliação e após 12 meses de terapia

\begin{tabular}{lcccc}
\hline Origem & $\begin{array}{c}\text { Músculo Temporal } \\
\text { Anterior Direito }\end{array}$ & $\begin{array}{c}\text { Músculo Temporal } \\
\text { Anterior Esquerdo }\end{array}$ & $\begin{array}{c}\text { Músculo Masseter } \\
\text { Direito }\end{array}$ & $\begin{array}{c}\text { Músculo Masseter } \\
\text { Esquerdo }\end{array}$ \\
\hline $\mathrm{A}(\mu \mathrm{V})$ & 8,3 & 35,3 & 25,3 & 31,5 \\
$\mathrm{~B}(\mu \mathrm{V})$ & 23,6 & 27,1 & 40,6 & 53,4 \\
\hline
\end{tabular}

Legenda: $A=$ média dos valores da atividade muscular registrada na mastigação habitual com uva passa nos 12 primeiros ciclos mastigatórios no período da avaliação; $B=$ média dos valores da atividade muscular registrada na mastigação habitual com uva passa nos 12 primeiros ciclos mastigatórios após 12 meses de terapia; $\mu \mathrm{V}=$ microvolt

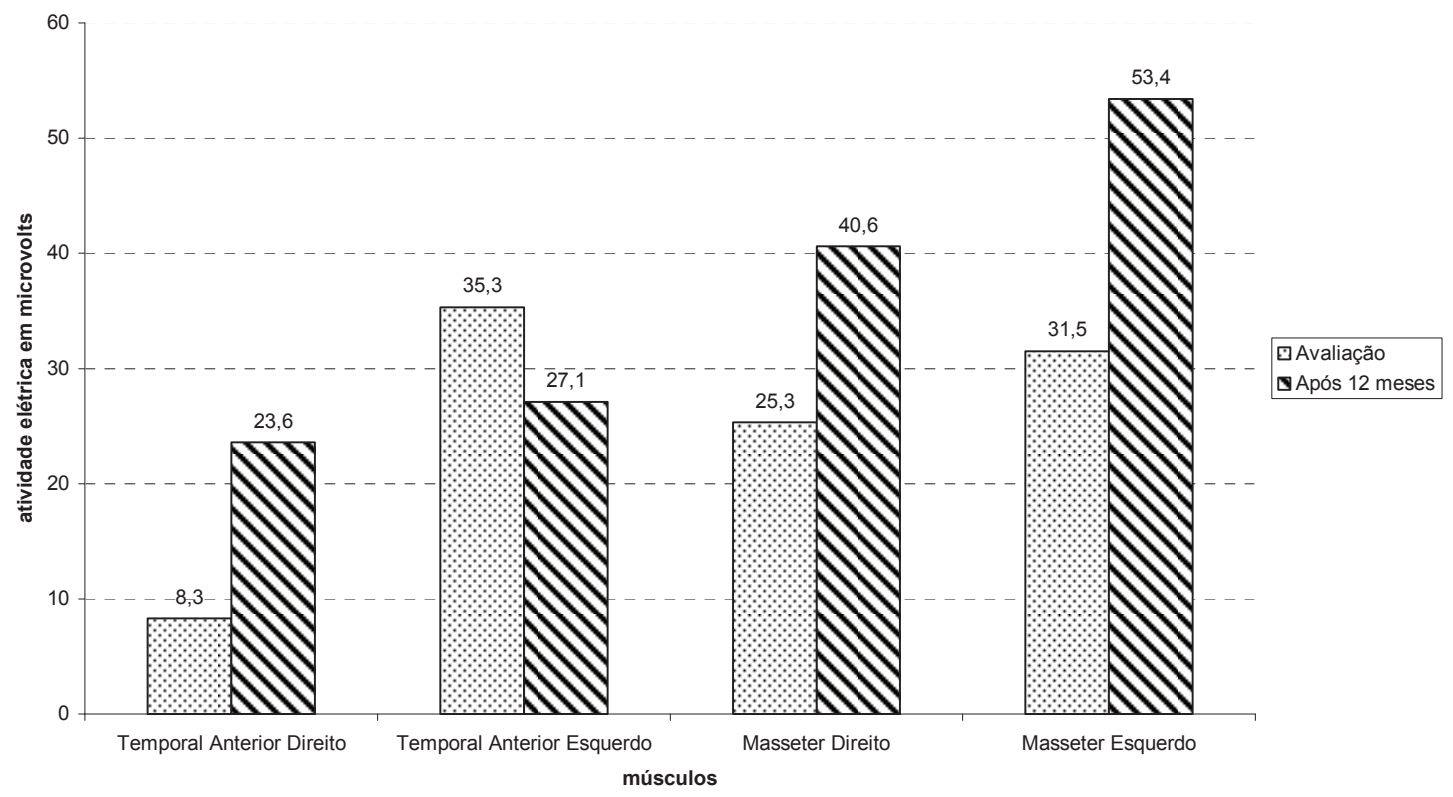

Figura 4 - Registro da atividade elétrica muscular através da eletromiografia na mastigação habitual provocada na avaliação e após 12 meses de terapia

sistema estomatognático. Talvez, este fator, como queixa da paciente e observado na avaliação, funcione como um mecanismo de proteção neuromuscular ${ }^{15,17}$.

Neste relato de caso, observa-se que a paciente, na avaliação, usava recursos não adequados, como pressão da mão direita na hemi mandíbula direita para tentar aliviar a dor na região e a cefaléia na região temporal direita, mas o desconforto aumentava. Ao longo do processo terapêutico a paciente inicia mecanismos de compensação mais efetivos, considerando os registros dos exames de eletromiografia, gerando um equilíbrio maior do sistema estomatognático ${ }^{18}$. Por isso, poderiam ser aventadas algumas hipóteses a serem consideradas no entendimento pleno das funções em questões, assim como a mastigação, ou abaixamento de mandíbula, considerando que, durante qualquer processo, ocorre a participação de vários sistemas.

A partir desse enfoque, vê-se que a excitação maior ou menor dos músculos, como abaixadores e levantadores da mandíbula, seria obviamente controlada pelo sistema nervoso central, talvez particularmente no nível da camada cerebral, incluindo o controle cortical e subcortical.

Para entender os mecanismos dos sistemas deve-se considerar a base da cibernética. A cibernética tem por objeto o estudo comparativo dos sistemas e mecanismos de controle automático, regulação e comunicação nos seres vivos e mesmo nas máquinas ${ }^{19}$.

Poder-se-ia dizer, como hipótese, que a paciente durante as terapias, adquiriu um ajuste constante de feedback negativo, e atingiu um equilíbrio no sistema estomatognático, considerando as limitações do caso.

A dor, como uma das queixas principais da paciente, focou o trabalho com as funções relacionadas ao sistema sensório motor oral e assim, estabeleceu-se respostas motoras que modificassem e adequassem as funções comprometidas. As maiores adequações dos movimentos da mandíbula 
possibilitaram modificações de espaços e movimentos de tecidos moles e da língua ${ }^{13}$ favorecendo que a paciente tivesse como consequência a sensação menor de nível de dor ${ }^{12}$.

Observa-se que conforme as funções, relacionadas ao sistema estomatognático, foram harmonizadas gradativamente, o grau de dor diminui.

O processo terapêutico priorizou a adequação do sistema mastigatório e das funções de sucção, deglutição, respiração e fala o que contribuiu para amenizar a dor e aumentar a abertura de boca.

Os resultados dos dados quantitativos das atividades elétricas dos músculos temporal anterior e masseter bilateral, através da eletromiografia, permitiram uma elaboração mais efetiva do planejamento terapêutico visando os déficits das funções e dos grupos musculares em questão ${ }^{20}$.

\section{CONCLUSÃO}

A eletromiografia de superfície não é um método invasivo e não interfere na atividade elétrica mus- cular. Ela não pretende estudar unidades motoras isoladas.

A tecnologia tem assumido um papel essencial. Os dados deste exame complementar foram valiosos por fornecer um diagnóstico diferencial da disfunção muscular, com maior objetividade, o que não permite na palpação manual e no discurso do paciente.

Desta forma, o relato de caso, aqui apresentado, fornece sua contribuição à área de Motricidade Orofacial, uma vez que interferências terapêuticas foram acrescidas pelos achados objetivos do exame de EMG, o que poderá servir como apoio para outros diagnósticos e planejamentos terapêuticos.

\section{AGRADECIMENTOS}

Agradecimento ao Centro de Diagnóstico e Tratamento da ATM (CDTATM) por possibilitar a realização dos exames de eletromiografia, disponibilizando suas instalações, funcionários e materiais.

Agradecimento ao Dr. Marcos Stávali, neurocirurgião, pelo esclarecimento e discussão do caso.

\begin{abstract}
Background: electromyography and therapeutic behavior. Procedures: this study was carried out with a woman, 45year old, after 4 months from being submitted to fronto-temporal craniotomy originated an aneurysm. The right anterior temporal muscle was removed from its insertion. After the surgery, the patient had dysfunction in temporal muscle and in temporo-mandibular joint, with reduction of the opening of mouth, pain while speaking and eating. Electromyography was used to quantitatively record the electrical activity of the temporal and masseter muscles in the initial evaluation and during the therapeutic process. Records were made at rest position, maximum occlusion and chew. They did miofuncional therapy throughout the process. Results: examination data showed a significant increase in the electrical activity of the right anterior temporal muscle and a reduction in the activity of the left anterior temporal muscle. The initial Record showed a lower electrical activity on the right side compared to the left. With the miofunctional exercises there was a more effective participation of the right anterior temporal muscle, greater openness of mouth, without pain, making easier chewing and speech tasks, harmonizing the stomatognathic system. Conclusion: comparative records concerning electromyography in different stages of the therapeutic process helped and directed the best therapy, achieving a balance concerning the functions of breathing, sucking, chewing, swallowing and speech related to the stomatognathic system, considering the limitations of the case.
\end{abstract}

KEYWORDS: Stomatognathic System; Temporomandibular Joint; Electromyography; Craniotomy

\section{REFERÊNCIAS}

1. Douglas CR. Fisiologia geral do sistema estomatognático. In: Douglas CR. Tratado de fisiologia aplicada a fonoaudiologia. Rio de Janeiro: Guanabara Koogan; 2006. p. 270-81.
2. Bianchini EMG. Avaliação fonoaudiológica da motricidade oral: anamnese, exame clínico, o que e por que avaliar. In: Bianchini EMG, organizador. Articulação temporomandibular: implicações, limitações e possibilidades fonoaudiológicas. Carapicuíba: Pró-Fono; 2000.p.191-253. 
3. Bianchini EMG, Andrade CF. A model of mandibular movements during speech: normative pilot study for the Brazilian Portuguese language. Cranio. 2006; 24(3):197-206.

4. Rigler I, Podnar S. Impact of electromyographic findings on choice of treatment and outcome. Eur $\mathrm{J}$ Neurol. 2007; 14(7):783-7.

5. Oncins MC. Mastigação: análise pela eletroneuromiografia e eletrognatografia. Seu uso na clínica fonoaudiológica [dissertação]. São Paulo (SP): Pontifícia Universidade Católica de São Paulo; 2004.

6. Rainoldi A, Melchiorri G, Caruso I. A method for positioning electrodes during surface EMG recordings in lower limb muscles. J Neurosci Methods. 2004; 134(1):37-43.

7. Oncins MC, Freire RMAC, Marchesan IQ. Mastigação: análise pela eletromiografia e eletrognatografia. Seuusonaclínicafonoaudiológica. Rev Dist Comun. 2006; 18(2):155-65.

8. Merletti R. Standards for reporting EMG data. J Electromyogr Kinesiol. 1999; 9(1):3-4.

9. Douglas CR. Fisiologia da postura mandibular e fisiologia da mastigação. In: Douglas CR. Tratado de fisiologia aplicada à saúde. São Paulo: Robe; 2002.p. 991-1006.

10. Jankelson RR. Clinical electromyography. In: Jankelson RR. Neuromuscular dental diagnosis and treatment. St. Louis: Ishiyaku Euroamerica; 1990. p.97-174.

11. Vazquez-Delgado E, Schmidt JE, Carlson CR, DeLeeuw R, Okeson JP. Psychological and sleep quality differences between chronic daily headache and temporomandibular disorders patients. Cephalalgia. 2004; 24(6):446-54.
12. Mongini F, Ciccone G, Ibertis F, Negro C. Personality characteristics and accompanying symptoms in temporomandibular joint dysfunction, headache, and facial pain. J Orofac Pain. 2000; 14(1):52-8.

13. Taucci RA, Bianchini EMG. Verificação da interferência das disfunções temporomandibulares na articulação da fala: queixas e caracterização dos movimentos mandibulares. Rev Soc Bras Fonoaudiol. 2007; 12(4):274-80.

14. Bianchini EMG, Paiva G, Andrade CRF. Movimentos mandibulares na fala: interferência das disfunções temporomandibulares segundo índices de dor. Pró-Fono. 2007; 19(1):7-18.

15. Dworkin SF, LeResche L. Research diagnostic criteria for temporomandibular disorders: review, criteria, examinations and specifications, critique. $J$ Craniomandib Disord. 1992; 6(4):301-55.

16. Bianchini EMG. Disfunção da articulação temporomandibular: relações com a deglutição e fala. Rev Dent Press Ortodon Maxilar. 1999; 4(5):55-60.

17. Felício CM, Melchior MO, Silva MAMR, Celeghini RMS. Desempenho mastigatório em adultos relacionado com a desordem temporomandibular e com a oclusão. Pró-Fono. 2007; 19(2):151-8.

18. Pereira JúniorFJ, VieiraAR, Prado R, MiasatoJM. Visão geral das desordens temporomandibulares. RGO. 2004; 52(2):117-21.

19. Douglas CR. Princípios de cibernética aplicada à fisiologia. In: Douglas CR. Tratado de fisiologia aplicada à saúde. São Paulo: Robe; 2002.p. 65-95. 20. Landulpho $A B$, Silva WAB, Silva FA. Eletromiografia e eletrosonografia no monitoramento das desordens temporomandibulares: relato de caso clínico. Rev Paul Odontol. 2003; 25(1):4-8.

DOI: 10.1590 / S1516- 18462009005000011

RECEBIDO EM: 02/04/2008

ACEITO EM: 03/09/2008

Endereço para correspondência:

Maristella Cecco Oncins

Rua Abílio Soares, 932

São Paulo - SP

CEP: 04005-003

E-mail: marisfono@uol.com.br 